\title{
Application of PALM-COEIN FIGO classification in diagnosis of abnormal uterine bleeding (AUB) patients
}

\author{
Sharda B Ahmed ${ }^{1, *}$, Sushma Mogri \\ ${ }^{\mathbf{1}}$ Associate Professor, ${ }^{\mathbf{A}}$ Assistant Professor, Dept. of Obstetrics and Gynaecology, American International Institute of Medical \\ Sciences, Udaipur, Rajasthan, India
}

*Corresponding Author:

Email: drshardaahmed@gmail.com

\begin{abstract}
Objective: The aim is to categorize women with AUB as per the PALM-COEIN classification system as this is a step towards cause based diagnosis and focused management of patients. The acronym PALM-COEIN comes from arranging 9 basic categories of the classification system. The PALM group comprises the structural entities, which can be measured visually or by using imaging techniques and histopathology. The COEIN group comprises the non-organic types which cannot be defined by imaging or histopathology.

Materials and Methods: The study comprises 350 women of reproductive age with AUB for minimum 3 months time span. It describes and observes AUB in amount, interval and frequency for women attending outpatient Gynae department of AIIMS, Udaipur (Raj) from Nov 16 to Oct 17. They were assessed on the basis of structured history, physical examination, local pelvis examination, investigations, USG findings and endometrial histopathological report. Cause of AUB was determined and treatment was given to the patient as appropriated by categorization done in agreement with the PALM-COEIN classification.

Results: The most prevalent cause of AUB was ovulatory dysfunction ( $\mathrm{n}=99,28.2 \%)$. Next common cause was leiomyoma $(\mathrm{n}=90,25.7 \%)$, followed by endometrial causes $(\mathrm{n}=52,14.5 \%)$, adenomyosis $(\mathrm{n}=30,8.5 \%)$, not yet classified $(\mathrm{n}=32,9.7 \%)$, Malignancy \& Hyperplasia ( $\mathrm{n}=28,8.1 \%)$, Polyp $(\mathrm{n}=9,2.5 \%)$, Iatrogenic $(\mathrm{n}=7,2.2 \%)$ and Coagulopathy $(\mathrm{n}=1,0.3 \%)$.

Conclusion: The PALM-COEIN classification helps to practically ascertain the cause of AUB, and thereby effectively adopt the correct treatment for AUB patients.
\end{abstract}

Keywords: Abnormal uterine bleeding, AUB, Classification system, Polyp leiomyoma, Adenomyosis, Ovulation, Malignancy.

\section{Introduction}

AUB is a significant clinical entity, affecting 14$25 \%$ women of reproductive age. ${ }^{1,2}$ It is a common and debilitating condition with high direct and indirect cost.

Since long, words such as menorrhagia, metrorrhagia and dysfunctional uterine bleeding have been used to describe AUB which are confusing, controversial and poorly defined. FIGO menstrual disorders working group proposed abandoning such terms for menstrual disturbances as such differing terms make it extremely difficult to interpret the patient's pathology or bleeding condition. ${ }^{3}$ The consensus established that AUB is an appropriate term because it includes different types of menstrual bleeding and at the same time implies that it should exclude bleeding from the cervix or the lower genital tract. It also proposed that AUB in non-pregnant women can be Acute or Chronic. ${ }^{5}$ Acute AUB requires prompt intervening to prevent further blood loss. Chronic AUB is bleeding from the uterine corpus persistent in the last 6 months and can be abnormal in terms of amount, interval or frequency. ${ }^{4}$

In recent years, concern regarding use of terminologies and definition around symptoms of AUB has increased. Simpler terms with clear meaning were needed that can be easily understood by the medical community. Therefore an improved classification system has been named by International Federation of Gynaecology and Obstetrics (FIGO) in 2011, which is called PALM-COEIN. ${ }^{6}$ PALM holds for the pathologies related to the uterine structural anomalies (polyp, adenomyosis, leiomyoma, malignancy and endometrial hyperplasia). COEIN holds for the pathologies unrelated with uterine structural anomalies (ovulatory dysfunction, coagulopathy, endometrial, iatrogenic, and unclassified). The PALM-COEIN system structurally evaluates AUB in women which helps to understand and identify causes and contributors to the symptoms. ${ }^{7}$

Moreover, PALM-COEIN system also helps to ascertain the role of multiple pathologies in any patient. Any coincidental pathology, with no symptoms, which has little contribution towards AUB can also be identified.

\section{Materials and Methods}

The present study is descriptive observational conducted at obgyn department of AIIMS, Udaipur (Raj) over a period of 1 year from Nov 16 to Oct 17. In this study, we have enrolled 350 non grand women of age group 15 to 55 years with irregular, unpredictable, abnormal volume, excessive or scanty duration or abnormal frequency of menses and inter-menstrual bleeding for a minimum of 3 months duration attending obgyn outdoors.

Detailed medical history (including menstrual \& obstetrics history, contraceptive use, drug use, any weight changes and systemic illness), along with physical examination, ultrasounds and other essential 
imaging techniques were undertaken as per the PALMCOEIN classification system.

Endometrium and hysterectomy specimen were obtained for histopathology where applicable. Women with vaginal bleeding because of cervical causes and pregnant women with bleeding were excluded from study. As per the PALM-COEIN classification system, the potential causes of AUB were established and then categorized accordingly. PALM-COEIN classification has the following categories:

P - Polyps were categorized either absent or present and diagnosed by history, perspeculum exam, ultrasound and/or histopathological exam.

A - Adenomyosis was identified based on medical history and ultrasound (asymmetrical myometrial appearance accompanied by a large uterus), and diagnosed by MRI and even on hysterectomy specimen. ${ }^{16}$

$\mathrm{L}$ - Leiomyoma was identified and diagnosed by ultrasound. This study includes only primary classification of leiomyoma, i.e., it reflects only the presence or absence of leiomyoma regardless of location, number and size.

M - If malignant or premalignant lesion was suspected, endometrial biopsy was performed for histopathology.

C - Coagulopathy was identified by patterned medical history, and diagnosed by coagulation test.

$\mathrm{O}$ - Ovulatory dysfunction included AUB cases of unpredictable time period and inconsistent amount of flow. It can be due to anovulation or disturbed ovulation. Endocrinopathies, polycystic ovarian syndrome, hypothyroidism, hyperprolactinemia and weight changes are included in this group. In few cases, bleeding was so unpredictable that medical intervention and emergency treatment was needed.

E - Endometrial causes include those AUB women who have predictable and cyclic bleeding typical of ovulatory cycles. The cause might be endometrial origin. It is a diagnosis of exclusion.

I - Iatrogenic group includes intrauterine contraceptives, gonadal steroids, anticonvulsant, antibiotics, antidepressants and anticoagulant drugs.

$\mathrm{N}$ - Not yet classified. It is inevitable that there will be pathologies that are either rare or poorly defined that do not easily fit within categories described earlier.

\section{Results}

Of the 6,300 women attending the gynaecology OPD during the study duration, $1170(18.6 \%)$ women put up with AUB. Of these women, 350 were studied in this report. All these cases were placed in the nine categories of PALM-COEIN classification.

Maximum patients, $47.7 \%$, were in the age group of 40 - 50 years and $37.4 \%$ were in the $30-40$ years age group (Table 1).

Majority of patients, $37.4 \%$, complained of heavy bleeding as chief complaint. $27 \%$ had irregular heavy bleeding and 22\% had frequent bleeding (Table 2).

As per the PALM-COEIN classification, ovulatory dysfunction $(28.2 \%)$ was the most prevalent cause of AUB in our study.

Simple ovarian cysts and PCOS were common sonographic findings. Hormone imbalance was common on endometrial histopathological report. Thyroid imbalance was also noted.

Next common category was Leiomyoma AUB-L $(\mathrm{n}=90,25.7 \%)$, followed by Endometrial AUB-E causes $(\mathrm{n}=52,14.5 \%)$, adenomyosis AUB-A $(\mathrm{n}=30,8.5 \%)$, Malignancy AUB-M $(\mathrm{n}=28,8.1 \%)$, Not classified AUB-N ( $\mathrm{n}=32,9.7 \%)$, Polyp AUB-P $(\mathrm{n}=9,2.5 \%)$, iatrogenic AUB-I $(\mathrm{n}=7,2.2 \%)$ and coagulopathy AUB$\mathrm{C}(\mathrm{n}=1,0.3 \%)$ (Table 3$)$.

Table 1: Age distribution of study population

\begin{tabular}{|l|c|c|}
\hline Age Group & Total Number & Percentage \\
\hline$<20$ years & 5 & $01.4 \%$ \\
\hline $20-30$ years & 15 & $04.2 \%$ \\
\hline $30-40$ years & 131 & $37.4 \%$ \\
\hline $40-50$ years & 167 & $47.7 \%$ \\
\hline$>50$ years & 32 & $09.1 \%$ \\
\hline
\end{tabular}

Table 2: Distribution of study population based on presented complaints

\begin{tabular}{|l|c|c|}
\hline \multicolumn{1}{|c|}{$\begin{array}{c}\text { Symptoms } \\
\text { (Complaints) }\end{array}$} & $\begin{array}{c}\text { Total } \\
\text { Number }\end{array}$ & Percentage \\
\hline $\begin{array}{l}\text { Heavy Menstrual } \\
\text { Bleeding }\end{array}$ & 131 & $37.4 \%$ \\
\hline $\begin{array}{l}\text { Irrregular Heavy } \\
\text { Bleeding }\end{array}$ & 95 & $27.0 \%$ \\
\hline $\begin{array}{l}\text { Intermenstrual } \\
\text { Bleeding }\end{array}$ & 7 & $02.0 \%$ \\
\hline Frequent Bleeding & 77 & $22.0 \%$ \\
\hline $\begin{array}{l}\text { Post Menopausal } \\
\text { Bleeding }\end{array}$ & 28 & $08.0 \%$ \\
\hline $\begin{array}{l}\text { Infrequent or Scanty } \\
\text { Bleeding }\end{array}$ & 12 & $03.4 \%$ \\
\hline
\end{tabular}

Table 3: Distribution of study population according to PALM-COEIN classification (total 350 patients)

\begin{tabular}{|c|c|c|c|}
\hline \multicolumn{2}{|r|}{ Causes } & Total Number & Percentage \\
\hline \multirow{4}{*}{ Structural } & Polyp (AUB-P) & 9 & $02.5 \%$ \\
\hline & Adenomyosis (AUB-A) & 30 & $08.5 \%$ \\
\hline & Leiomyoma (AUB-L) & 90 & $25.7 \%$ \\
\hline & Malignancy (AUB-M) & 28 & $08.1 \%$ \\
\hline \multirow{2}{*}{$\begin{array}{l}\text { Non } \\
\text { Structural }\end{array}$} & Coagulopathy (AUB-C) & 1 & $00.3 \%$ \\
\hline & Ovulatory Dysfunction (AUB-O) & 99 & $28.2 \%$ \\
\hline
\end{tabular}




\begin{tabular}{|c|c|c|c|}
\hline & Endometrial (AUB-E) & 52 & $14.5 \%$ \\
\cline { 2 - 4 } & Itrogenic (AUB-I) & 7 & $02.2 \%$ \\
\cline { 2 - 4 } & Not Yet Classified (AUB-N) & 32 & $09.7 \%$ \\
\hline
\end{tabular}

Table 4: Comparison of distribution of causes

\begin{tabular}{|l|c|c|c|c|c|c|}
\hline \multicolumn{1}{|c|}{ Causes } & Category & Present Study & Gouri et al & Goel et al & Qureshi \& Yusuf & Ratnani et al \\
\hline Polyp & $\mathrm{P}$ & $09(02.5 \%)$ & $06(02.0 \%)$ & $08(02.7 \%)$ & $30(03.0 \%)$ & $40(13.3 \%)$ \\
\hline Adenomyosis & $\mathrm{A}$ & $30(08.5 \%$ & $38(12.7 \%)$ & $28(09.3 \%)$ & $150(15 \%)$ & $60(20.0 \%)$ \\
\hline Leiomyoma & $\mathrm{L}$ & $90(25.7 \%)$ & $74(24.7 \%)$ & $68(22.7 \%)$ & $250(25 \%)$ & $105(35 \%)$ \\
\hline $\begin{array}{l}\text { Malignancy or } \\
\text { Hyperplasia }\end{array}$ & $\mathrm{M}$ & $28(08.1 \%)$ & $15(05.0 \%)$ & $08(02.7 \%)$ & $66(06.7 \%)$ & $65(21.6 \%)$ \\
\hline $\begin{array}{l}\text { Coagulopathy } \\
\text { Ovulatory } \\
\text { Dysfunction }\end{array}$ & $\mathrm{C}$ & $01(00.3 \%)$ & $09(03.0 \%)$ & $03(01.0 \%)$ & $03(03.0 \%)$ & $02(00.6 \%)$ \\
\hline Endometrial & $\mathrm{O}$ & $99(28.2 \%)$ & $81(27.0 \%)$ & $85(28.3 \%)$ & $236(24 \%)$ & $60(20.0 \%)$ \\
\hline Iatrogenic & $\mathrm{I}$ & $52(14.5 \%)$ & $27(09.0 \%)$ & $62(20.7 \%)$ & $48(05.0 \%)$ & $12(04.0 \%)$ \\
\hline Not Yet Classified & $\mathrm{N}$ & $32(02.2 \%)$ & $24(08.0 \%)$ & $13(04.3 \%)$ & $53(06.0 \%)$ & $03(01.0 \%)$ \\
\hline
\end{tabular}

\section{Discussion}

The aim to conduct this study was to test the efficiency and practicality of PALM-COEIN classification system in clinical practice in determining the cause of disease and treatment modality for patient showing AUB at outpatient department. The new FIGO classification was developed to clear long standing apprehension regarding terminologies and definitions related to AUB. These terms referred to symptoms or diagnosis, were not clear, and on the contrary these terms created confusion in treatment of AUB cases.

This study focuses to categorize the patient of AUB as per the PALM-COEIN classification and is similar to studies by Khrouf et al $;{ }^{8}$ Munro et al $;{ }^{6}$ Madha et $\mathrm{al}^{9}{ }^{9}$ Bahamondes and Ali. ${ }^{10}$ With this, necessary investigations can be easily done and better management of specific causes can be planned.

In present study, most of the patients presented with AUB were in age group 40-50 years (47.7\%) and $30-40$ years $(37.4 \%)$. Of the presented complaints, heavy menstrual bleeding (37.4\%) was the most common, followed by irregular heavy bleeding (27\%) and frequent bleeding $(22 \%)$. It was also noted that infrequent and scanty bleeding was more common in obese and PCOS women. ${ }^{11}$

According to study done by Gouri et $\mathrm{al}^{11}$ in May'16, category which had the most patients was ovulatory dysfunction (27\%), followed by leiomyoma $(24.7 \%)$. In study done by Goel $\mathrm{P}$ et $\mathrm{al},{ }^{12}$ ovulatory dysfunction was found to be the most common cause of AUB (28.3\%) followed by leiomyoma (22.7\%). In present study also, ovulatory dysfunction was found to be the most common cause of AUB (28.2\%) (Table 4). PCOS, hormonal dysfunction, thyroid dysfunction, simple ovarian cyst were included in this category.

In study done by Qureshi and Yusuf ${ }^{13}$ in 2013, leiomyoma was most common category (25\%) followed by ovulatory dysfunction (24\%). In study for Ratnani R et $\mathrm{al}^{14}$ in Sep' 17 , leiomyoma (35\%) was the most common cause of AUB, followed by malignancy and hyperplasia, adenomyosis and ovulatory dysfunction. In present study, leiomyoma was found in $25.7 \%$ of women and endometrial category was applied for $14.5 \%$ patients. In study done by Gouri et al and Goel $\mathrm{P}$ et al, endometrial causes were found on $9 \%$ and $20.7 \%$ respectively.

This study encapsulates the ease of use and implementation of this classification system. Moreover, treatment of pathology was easier where the cause of AUB was determined. In present study, we could understand the major causes of AUB grouped into structural and non-structural cause. In both groups, management plans were different, hence management was more focused and tailored to specific cause. The major disadvantage was in cases of patients who belonged to AUB-N category because treatment is vague in this category in absence of diagnosis. Also, COEIN part of classification needs further improvement through elaborate research.

\section{Conclusion}

To identify the exact cause is essential to successfully treat patients with AUB. The PALMCOEIN classification helps to practically ascertain the cause of AUB, and thereby effectively adopt and plan for focused treatment of patients.

It is also important to regularly improvise and improve this classification system in line with changes and improvements in medical science and technology. It also needs to adapt to the available options as per demographics.

\section{Conflict of Interest: None}

\section{References}

1. Fraser IS, Langham S, Uhl Hochgraeber $\mathrm{K}-$ Health related quality of life and economic burden of abnormal uterine bleeding. Expert Rev Obstet Gynaecol 2009;4:179-89. 
2. Shapley M, Jordan K, Croft PR - An epidemiological survey of symptoms of menstrual loss in the community. Br J Gen Pract 2004;54:359-63.

3. Munro MG, Critchley HOD, Fraser IS - The flexible FIGO classification concept for underlying causes of abnormal uterine bleeding. Semin Reprod Med 2011;29:391-99.

4. Munro MG, Broder M, Critchley HOD, Matteson K, Haththotuwa R, Fraser IS - An international response to questions about terminologies, investigation, and management of abnormal uterine bleeding: use of an electronic audience response system. Semin Reprod Med 2011;29:436-45.

5. Fraser IS, Critchley HOD, Broder M, Munro MG - The FIGO recommendation on terminologies and definitions for normal and abnormal uterine bleeding. Semin Reprod Med 2011;29:383-90.

6. Munro MG, Critchley HOD, Broder M, Fraser IS - FIGO working group on menstrual disorders. FIGO classification system (PALM-COEIN) for causes of abnormal uterine bleeding in nongravid women of reproductive age. Int J Gynaecol Obstet 2011;113(1):313.

7. Munro MG, Critchley HOD, Fraser IS - The FIGO systems for nomenclature and classification of causes of abnormal uterine bleeding in the reproductive years: who needs them? Am J Obstet Gynaecol 2012;207(4):259265.

8. Khrouf M, Terras K - Diagnosis and management of formerly called "dysfunctional uterine bleeding" according to PALM-COEIN FIGO classification and the new guidelines. J Obstet Gynaecol India 2014;64:388-93.

9. Madhra M, Fraser IS, Munro MG, Critchley HOD Abnormal uterine bleeding: advantages of formal classification to patients, clinicians and researchers. Acta Obstet Gynaecol Scand 2014;93:619-25.

10. Bahamondes L, Ali M-Recent advances in managing and understanding menstrual disorders. F 1000 Prime Rep 2015;7:33.

11. Gouri SRS, Lakshmi PV, Rani NG, Kumar NA Categorization of the causes of AUB according to PALM-COEIN classification. 107 International Journal of Scientific Study 2016;4(2)

12. Goel P, Rathore SB - PALM-COEIN FIGO classification for diagnosis of abnormal uterine bleeding. Sch J App Med Sci 2016;4(8A):2771-2773.

13. Qureshi FU, Yusuf AW - Distribution of causes of abnormal uterine bleeding using the new FIGO classification system. J Pak Med Assoc 2013;63:973-75.

14. Ratnani R, Meena N - A clinico-pathological analysis of causes of abnormal uterine bleeding according to PALMCOEIN classification. JMSCR Sep'2017;5(09):2819628200.

15. Sharma JB, Yadav M - New ground breaking International Federation of Gynaecology and Obstetrics's classification of abnormal uterine bleeding. J Midlife Health, Jan-Mar 2013;4(1):42-45

16. Hasdemir PS, Ulusoy M, Cailk E, Solmaz U, Gevenal T Assessment of patients with abnormal uterine bleeding in the reproductive period according to PALM-COEIN classification system. Scient Open Access Journal, Mar 2016. 